\title{
BRAZILIAN AIRPORTS NETWORK EVALUATION
}

Deivison da Silveira Pereira dspereira@id.uff.br

Federal Fluminense University, Niterói, RJ, Brazil

Joao Carlos Correia Baptista Soares de Mello

joaocsmello@gmail.com Federal Fluminense University, Niterói, RJ, Brazil

\section{ABSTRACT}

Goal: This paper presents an analysis of the Brazilian air network based on the measure of $h$ centrality.

Design / Methodology / Approach: The purpose of this study is to define and determine the central network using the concepts of h-centrality. Method adapted from graph theory concepts with bibliometrics, especially the $\mathrm{h}$-index. From the center of this index will be listed the most used airports to define the Brazilian central network and thus determinate the type h-index of Brazil.

Results: The main airports in the results represent more than $50 \%$ of the homologated flights in Brazil.

Limitations of the investigation: The centrality measure presents the situation at the moment when the data were analyzed. In the original h-index this notion reflects a history of the articles published by each

author, but in the case of airports the market dynamics changes the behavior of the network.

Practical implications: This model of air flight frequencies assists in public policy guidelines and planning both in air traffic control and in the verification of system impacts.

Originality / Value: The method seeks to provide the list with main important airports without any prior definition by a decision maker.

Keywords: Air transport; H-Index; H-Centrality. 


\section{INTRODUCTION}

The air transport industry performs one third, in value, of global cargo trade. On the other hand, in Brazil, this sector responsible for only $1.4 \%$ of the country's GDP (International Air Transport Association, 2016). In this industry, airports play a strategic role to both government and private companies (Bel and Fageda, 2008; Doganis, 1992).

Indeed, the availability of Brazilian airports and the coverage of domestic air network are adequate, with a distribution that mirrors population concentration, according to McKinsey and Company (2010). There are approximately 2,498 airports (including landing areas) in Brazil, i.e., the second largest number of airports in the world, only behind the United States. However, only 128 of them are commercially explored, and 34 airports are used for international connections. Moreover, only three, of all commercial airports, are rated among the top 100 in the world (International Air Transport Association, 2016). In fact, the quality of airport infrastructure in Brazil is ranked by executives in 19th place, out of 23 countries from Latin America and Caribbean, and $112^{\text {th }}$ globally (International Air Transport Association, 2016). Wolff et al. (2019) highlight air transport used as mode of freight has less time of travel and greater security, but at a high cost which is suitable to high added value products.

In terms of historical data, Graph 1 shows the sector's growth over the past few years, regarding the number of flights, as well as the proportion of the domestic and the international market, based on data from the National Civil Aviation Agency - ANAC (in Portuguese, Agência Nacional de Aviação Civil, 2016). We could observe that the number of flights increased 31.6\%, from 2007 to 2016, although its peak occurred in 2012. We highlight this is a sector with great importance for Brazilian economics (Pereira et al., 2017). Moreover, the proportion of international flights grew considerably.

The aim of the paper is to analyze the Brazilian air network according to the measure of h-centrality graphs, proposed by Pereira et al. (2015a), where the h-index concepts and graph theory were adapted to form the proposed measure. We seek to afford a list with main airports in the air network considering the characteristics from relevance and availability.

The main Brazilian airports is listed and checked to define main central network based on the data of the Brazilian airports and their connectivity. With central network defined, a second stage of the $h$-index is generated to create a general $\mathrm{h}$-index for the Brazilian airport network.

\section{CENTRALITY AND H-INDEX}

The definition of the central points of a network involves the identification of its most impacting points, which can be calculated based on centrality measures (Ercsey-Ravasz et al., 2012). Studies on centrality have a variety of application such as academic evaluation (Batista et al., 2018) or even a general industry assessment (Pereira et al., 2018b).

In general, centrality evaluates the relative importance of a vertex in a network (Bergiante et al., 2011), and can be measured in several different ways, with different meanings and interpretations. Some centrality measures are related to the h-centrality: the centrality of degree that measures the amount of edges connected to the vertex; the centrality of

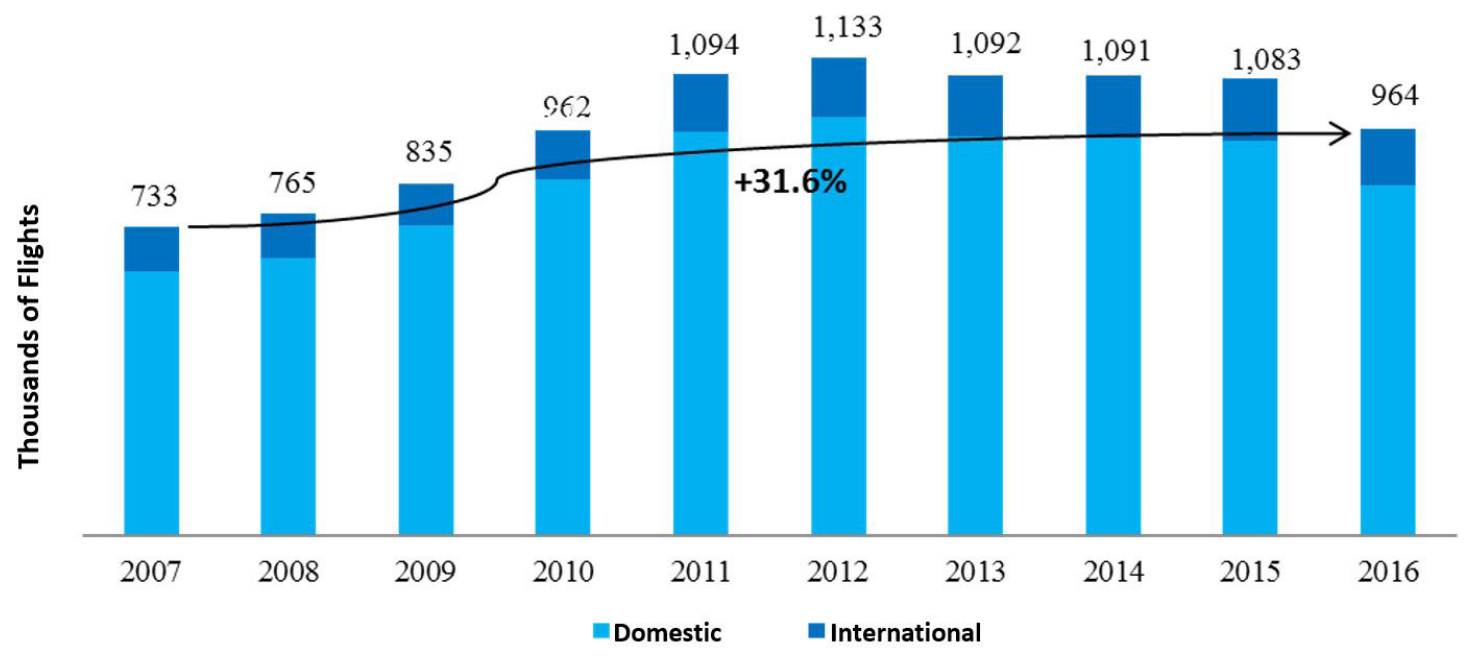

Graph 1. Evolution of the number of flights in Brazil 
layers that measures the influence of the neighbors, but by exclusion of the lower degree vertices, and the eigenvector centrality that measures the influence of the neighbors by linear combination.

\section{Air network centralities}

Centralities studies on airport network involve definitions of hub center points and air routes. The concepts of hubs are explored from the need for models to define routes in those location with high connectivity and demand, according to Jaillet et al. (1996). Yaru and Lina (2012) indicate the airport hubs influence the cargo sector as well where the greater frequency of flights easy the deliveries. Pereira et al. (2018a) evaluate the network from a Brazilian airline company comparing classical centralities measures and providing the main airports through multicriteria method.

Hansen (1990) verifies the choice of a hub and spoke network model by a company involves decisions looking for gains in scale for its operations as well as competition judgment where diverse players seek to maximize their profit.

Nevertheless, competition from large companies with low cost airlines weakens the margins at these big airports to large ones, as seen by Fageda (2014), in an analysis of the European network. This also influences the efficiency of companies according to Marti et al. (2015).

Fageda et al. (2015) find that low-cost airlines tend to take on greater gains with point-to-point routes where they work practically in monopoly, and large companies tend to focus passengers on hubs to better utilize the air network.

Though, as seen by Fageda et al. (2015), large companies are making alliances, such as Delta acquiring GOL shares (2011), or creating low-cost subsidiaries such as Lufthansa on creation of Germanwings in 2012. Indeed, some aspects aid in the implementation of low-cost routes, as seen by Lu and Mao (2015) in the analysis of these factors in Taiwan, as the price government, the operational supporting efficiency and the airport authority with the policies. As indicated by Zhang et al. (2014) the high prices in the hubs pressure the fee of airline tickets and end up impacting the profitability of large companies.

H-index

Created for evaluating the performance of researchers, the $\mathrm{H}$-index or Hirsch index was developed in 2005 by Argentine physicist Jorge Eduardo Hirsch, a professor at the University of California. $\mathrm{H}$-index is widely used in bibliometrics research. Till then, the evaluation of researchers was done either considering the number of articles or the quantity of citations, the $h$-index provides an evaluation using both measures, being variable over time.

To illustrate the large volume of articles covering the h-index since creation in 2005 , in the Scopus database more than 270 scientific papers present in their scope themes related to this index. Many of these documents are linked to the scientific journals that deal with metric studies of information, such as bibliometric, scientometry and informetric.

Among these studies, some papers have great relevance for the scientific community, such as Van Raan (2006) who proposed the analysis of the correlation between the index and several standard bibliometric indicators and with results obtained through the judgment method known as peer review.

Some researches still highlight the predictive capacity of the h-index. Schreiber (2013) recalls that Hirsch (2007) identified a correlation between $\mathrm{h}$-index values after 12 years and after 24 years of a research career, noting that the Hirsch index, compared to the other indicators mentioned in the study, has the capacity to predict the future of scientific production with greater precision.

Rubem et al. (2015) performed a h-index analysis on groups of researchers also recall that $h$-index in 2005 significantly impacted bibliometric research, and after the publication of the seminal article, many researchers dedicated themselves to developing variation, extensions and generalizations of the Hirsch index.

Pereira et al. (2015b) used the h-index and performed a post-analysis with multicriteria methods to evaluate the scientific production of the Department of PostGraduation in Production Engineering of the Federal Fluminense University, verifying a research ranking for the department.

Reis et al. (2017) use $h$-index core to determine the Olympic powerful countries with data from the Olympic Games held in the city of Rio de Janeiro in 2016, considering importance for medals in different modalities.

Based on the definition of the central network and the $\mathrm{h}$-index of the Brazilian air networl, Pereira et al. (2015a) present a proposal to adapt h-index for vertex centrality determination as described in the topic section 2.3 of this paper. 
H-centrality

The centrality based on the h-index (Pereira et al., 2015a) provides e central vertices by adjusting the bibliometric concepts of the $\mathrm{h}$-index. This method is similar to degree centrality, which measures the number of adjacent vertices for each vertex analyzed, so-called neighbors.

From a graph $\mathrm{G}=(\mathrm{V}, \mathrm{E})$, where $\mathrm{V}$ is the set of $\mathrm{n}$ vertices $v_{i}$ and $E$ is the set of $m$ edges $\left(v_{i}, v_{j}\right)$, which each edge is formed by a pair of vertices of $\mathrm{V}$, in this case $\mathrm{v}_{\mathrm{i}}, \mathrm{v}_{\mathrm{j}} \in \mathrm{V}$. We have $h$ - centrality for $v_{i}$, defined by $C_{H}\left(v_{i}\right)$, is obtained in the ordering of the $j$ vertices $v_{j}$ decreasing by the number of connections (edges), so $\sum v_{i} v_{j}$ in module. The h-centrality will be the number $\mathrm{j} \leq \sum \mathrm{v}_{\mathrm{i}} \mathrm{v}_{\mathrm{j}}$. In Figure 1 is presented illustratively contrast of the $\mathrm{h}$-index with $\mathrm{h}$ - centrality. In the original h-index proposed by Hirsch (2005), $v_{i}$ is the researcher, $v_{j}$ is article, $\sum \mathrm{v}_{\mathrm{i}} \mathrm{v}_{\mathrm{j}}$ is the quantity of citations of article $\mathrm{v}_{\mathrm{j}}$ and $\mathrm{j}$ is the order given decreasing by the number of citations.

The $\mathrm{j}$ neighbors vertices of $\mathrm{v}_{\mathrm{i}}$ which have $\sum \mathrm{v}_{\mathrm{i}} \mathrm{v}_{\mathrm{j}}$ at least the number $h$ form the core list of vertices $v_{i}$ (Burrell, 2007). The $\mathrm{h}$-centrality differs from the other methods in literature since it has the prioritization by the quantity $h$ of the adjacent vertices. This method presents the impact of the vertex analyzed, distinct from measure of degree or the measure of closeness which consider only the adjacent connections without to carry out the ordering.

We verified some studies which analyze the structure of the network of air routes through centrality measures, as Wittmer and Beritelli (2011) in an evaluation of Australia. They also verify and determine the important hubs in the country, as well as the influence on the network of the airlines and also analyze the routes detailing competitions among companies.

In another approach, Wang et al. (2011) verify China's air network considering the measures of centrality for central cities directly linked to cities with greater economic activity. Therefore, the analysis of the companies' strategies of action depends on a greater management of the network of action.

\section{STUDY OF BRAZILIAN AIR NETWORK}

The data used in this study are based on the HOTRAN table, where the national civil aviation regulator ANAC (National Civil Aviation Agency) defines all regular commercial flights (domestic and international) for transporting of passengers including cargo. The table data was extracted from 08 August 2015 , where the direct routes for all the airports were listed.

In this paper a flight will be defined only as direct connection two airports, according to the method used by Pereira et al. (2010). They verify a model for calculation of aerial accessibility of airports from the direct connections offered. Illustrating this concept of flight, consider the flight JJ3307 operated by TAM Linhas Aéreas with following itinerary: GIG - Galeão Airport, Rio de Janeiro / RJ x FOR - Fortaleza Airport / CE x Natal - RN x GRU Airport - Airport of Guarulhos / SP. In this case, 1 flight will be counted for each direct flight origin, i.e.: 1 flight to the GIG, referring to the GIG x FOR flight, 1 flight to the FOR, referring to the FOR $x$ NAT and 1 flight to the NAT, section NAT $x$ GRU.

The code used in this study is following the IATA (International Air Transport Association), which are better known for being the same used for ticket reservation.

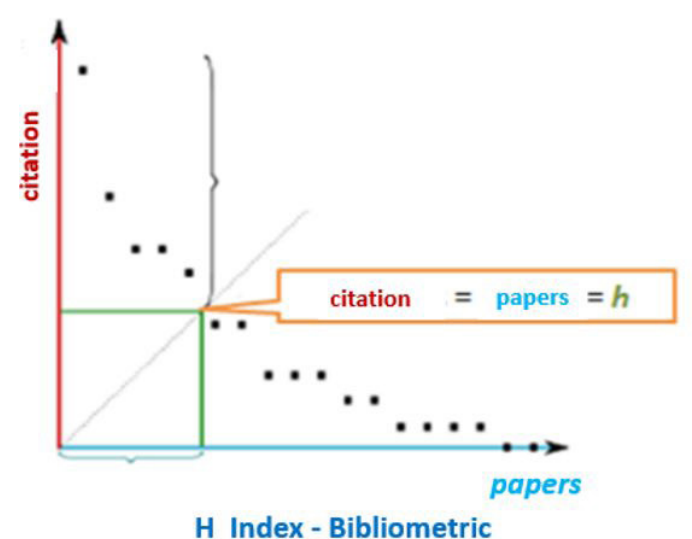

H Index - Bibliometric

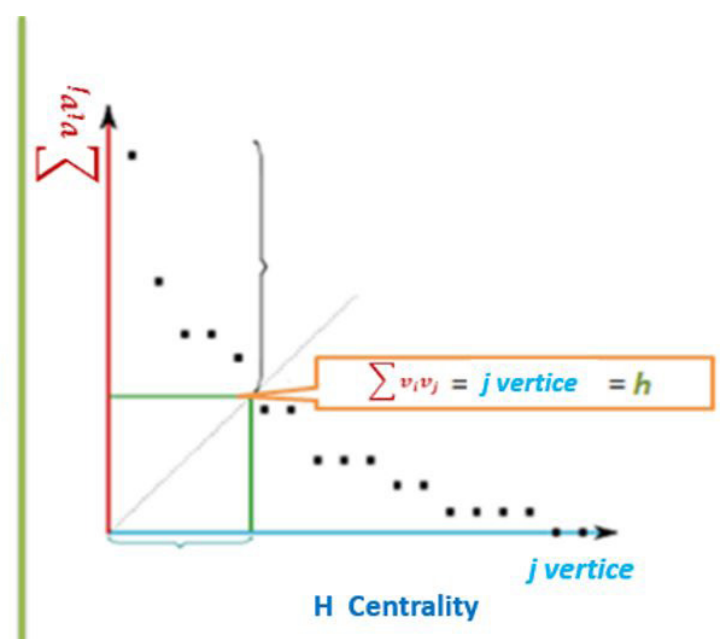

Figure $1 . \mathrm{H}$-index versus $\mathrm{H}$-centrality comparative 
For example, for Santos Dumont Airport, which airport is in Rio de Janeiro-RJ, the code is SDU.

Some steps are followed before the determination of the Brazilian central network, according to the h-centrality measure. We start with data processing, where arbitrarily defined commercial flights of passengers with departures on Mondays, excluding from the HOTRAN table the freight flights and the postal network. Mondays present the largest number of destinations served and therefore the we can analyze the wide-ranging case of the network.

\section{H-CENTRALITY NETWORK}

The definition of the central network based on the h-centrality is from the centrality measure of the centrality each airport in the Brazilian air network.

$\mathrm{H}$-centrality analysis for air transport shall be done with data collected in a same period for all the considered airports, so the characteristics is not influenced by seasonality of the air transport market.

Contrasting the original $\mathrm{h}$-index that considered articles and citations where only citation increase, airports flights can be created or canceled in the same way that route destinations can no longer be served or be included according to company strategies.

Flight data considers departures on a day of the week to maintain the same order of magnitude of destinations and quantity of existing flights. In this line, we adapt from the original definition between articles and citations, transformed into destinations and flights respectively. First, we chose the day of the week that presents the largest number of destinations served, in this case was chosen Mondays.

Thus, with destination and flight data for a certain day of the week, a list of flights to each destination of the airport to be analyzed should be made in descending order. Figure 2 presents the $\mathrm{h}$-index comparison and h-centrality applied to airports, as defined by Pereira et al. (2015a).

\section{H-centrality calculation}

Table 1 presents the case of SDU - Santos Dumont Airport, located in the city of Rio de Janeiro, state of Rio de Janeiro, Brazil, as Pereira et al. (2015a). This table shows the destinations of flights departing from this airport, with the respective quantities of flights approved for Mondays, in descending order.

From Table 1 there are 6 destinations with at least 6 flights departing from Santos Dumont, while the other destinations have less than 6 flights, which leads to the h-index of 6 , as highlighted in the table. Here in, the airports list formed by the $h$-index number is called core list. This core list to verify the impact of the airport by the number $h$, as well as in the identification of the main destinations for each origin, given its dispersion of performance So this method by being a factor of influence in the network, is called as variation to the centralities of eigenvector and layers.

\section{H-centrality connectivity}

Through the h-centrality core of each airport is possible to analyze the connectivity between them, verifying the influence of each one. Additionally, h-centrality core list

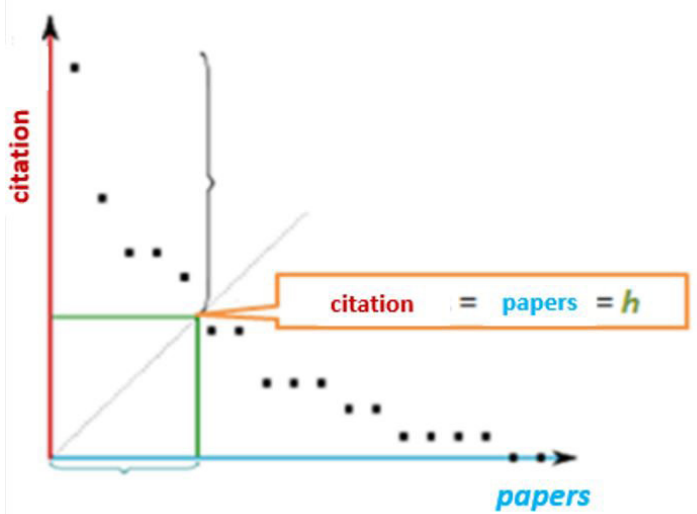

H Index - Bibliometric

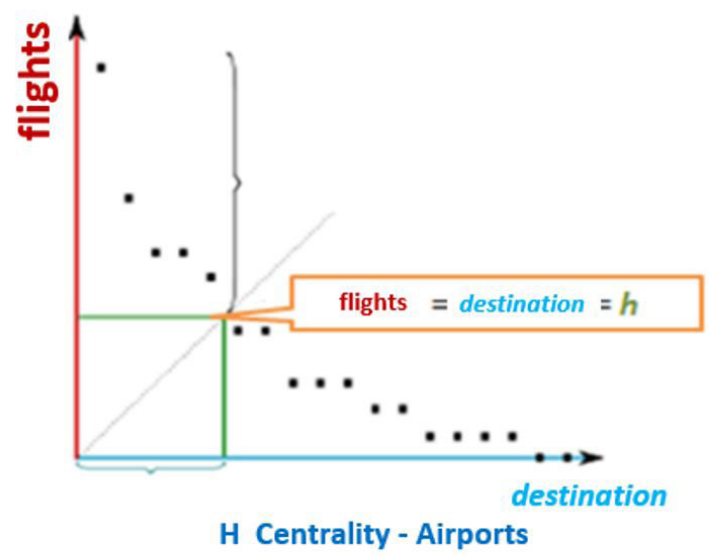

Figure 2. $\mathrm{H}$ index versus $\mathrm{H}$ centrality applied to airports case 
could be provided without a prior evaluation from the analyst. The importance of the index core can be seen in Table 1, where the core is formed by the list with at least $h$ flights, representing respectively $92 \%$ of the total number of flights.

The creation of the subnet will indicate the main connections within the network analyzed. Initially, for this analysis will be chosen the core SDU presented in Table 1 that presents Table 2 with the relation of destinations in the core of each origin.

Next, each for destination found the cores are analyzed. In the case presented in Table 2, the core airports of the SDU will be included in the Depart column: CGH, BSB, GRU, CNF, VCP and VIX. For each one, the $h$-index and the list of destinies that combine each core is checked.

H-centrality results

A matrix of adjacency with the core $\mathrm{h}$-index of each airport is formed from the connections between the airports. However, the central network is defined by the square matrix, where you need to exclude the secondary airports, which are those that are not present in the airports core list.

In this, we define a starting point and preferably starts at one of the largest airports in terms of the number of flights on the network. This method shall probably cover the final central network. In this study, the starting point was the SDU - Santos Dumont Airport. According to Table 1, it has at its core the following airports: Congonhas, Brasilia, Campinas, Guarulhos, Confins and Vitória, which have at least 6 regular flights by day. Table 3 presents the list ordered by the h-centrality measure of the 31 airports that form the central network of the Brazilian air network.

All 15 major Brazilian airports in terms of number of flights are within Table 3, and the importance of this central network is given by the representativeness of more than $90 \%$ of the approved flights within the Brazilian network.

Figure 3 obtained by the Netdrawn software (Borgatti, 2002) presents the graph from the matrix of square adjacency of the connections of the core $h$ of each airport in Table 3. The representation of the network seeks to approximate the geographic disposition each in the Brazilian territory.

As shown in Figure 3, and compared to Table 3, the main airports with h-type index up to 7 (Guarulhos, Congonhas, Brasilia, Galeão, Confins and Viracopos) Theses airports are located (except Brasília) in the Southeast region and these represent more than $50 \%$ of the homologated flights in Brazil.

We noted that h-centrality network not present representation of all Brazilian States. The states of Rio Grande do Norte, Roraima, Sergipe and Tocantins, States located in the North and Northeast of Brazil, did not present

Table 1. Flights and cities for SDU case

\begin{tabular}{|c|c|c|c|}
\hline CODE & Airport & Flights & Position \\
\hline CGH & Congonhas Airport - São Paulo/SP & 73 & 1 \\
\hline VCP & Viracopos Airport - Campinas/SP & 22 & 2 \\
\hline BSB & Brasília/DF Airport & 20 & 3 \\
\hline GRU & Guarulhos/SP Airport & 18 & 4 \\
\hline CNF & Confins - Belo Horizonte/MG Airport & 17 & 5 \\
\hline VIX & Vitória/ES Airport & 4 & 7 \\
\hline CWB & Curitiba/PR Airport & 3 & 8 \\
\hline POA & Porto Alegre/PA Airport & 2 & 9 \\
\hline FLN & Florianópolis/SC Airport & 1 & 10 \\
\hline UDI & Uberlândia/MG Airport & 1 & 1 \\
\hline SSA & Salvador/BA Airport & 1 & 12 \\
\hline GYN & Goiânia/GO Airport & 1 & 13 \\
\hline NVT & Pampulha Airport - Belo Horizonte/MG & 1 & 14 \\
\hline Total & Navegantes/SC Airport & 174 & 10 \\
\hline
\end{tabular}

Table 2. Core central destinations for SDU

\begin{tabular}{|c|c|c|c|c|c|c|}
\hline \multirow[b]{2}{*}{ From } & \multicolumn{6}{|c|}{ To } \\
\hline & $\mathrm{CGH}$ & BSB & GRU & CNF & VCP & VIX \\
\hline SDU & 73 & 20 & 18 & 17 & 22 & 10 \\
\hline
\end{tabular}


Table 3. Brazilian airports H Network

\begin{tabular}{|c|c|c|c|}
\hline H position & H Centrality & Code & Airport \\
\hline 1 & 11 & GRU & Guarulhos - SP Airport \\
\hline 2 & 9 & $\mathrm{CGH}$ & Congonhas Airport - São Paulo - SP \\
\hline 3 & 8 & BSB & Brasília - DF Airport \\
\hline 3 & 8 & GIG & Galeão Airport - Rio de Janeiro - RJ \\
\hline 4 & 7 & CNF & Confins - MG Airport \\
\hline 4 & 7 & VCP & Viracopos Airport - Campinas - SP \\
\hline 5 & 6 & BEL & Belém - PA Airport \\
\hline 5 & 6 & CGR & Campo Grande - MS Airport \\
\hline 5 & 6 & CWB & Curitiba - PR Airport \\
\hline 5 & 6 & FOR & Fortaleza - CE Airport \\
\hline 5 & 6 & SDU & Santos Dumont Airport-Rio de Janeiro-RJ \\
\hline 6 & 5 & POA & Porto Alegre - RS Airport \\
\hline 6 & 5 & REC & Recife - PE Airport \\
\hline 6 & 5 & SSA & Salvador - BA Airport \\
\hline 6 & 5 & VIX & Vitória - ES Airport \\
\hline 7 & 4 & CGB & Cuiabá - MT Airport \\
\hline 7 & 4 & MAO & Manaus - AM Airport \\
\hline 7 & 4 & FLN & Florianopolis - SC Airport \\
\hline 7 & 4 & GYN & Goiania - GO Airport \\
\hline 7 & 4 & RAO & Riberão Preto - SP Airport \\
\hline 7 & 4 & SLZ & São Luis - MA Airport \\
\hline 8 & 3 & PLU & Pampulha Airport - Belo Horizonte - MG \\
\hline 8 & 3 & LDB & Londrina - PR Airport \\
\hline 8 & 3 & NVT & Navegantes - SC Airport \\
\hline 8 & 3 & $\mathrm{PVH}$ & Porto Velho - RO Airport \\
\hline 8 & 3 & STM & Santarém - PA Airport \\
\hline 8 & 3 & THE & Teresina - PI Airport \\
\hline 9 & 2 & ATM & Altamira - PA Airport \\
\hline 10 & 1 & ITB & Itaituba - PA Airport \\
\hline 10 & 1 & $\mathrm{MOC}$ & Montes Claros - MG Airport \\
\hline 10 & 1 & $\mathrm{MCP}$ & Macapá - AP Airport \\
\hline
\end{tabular}

direct connections with a significant number of flights to be included in the central $\mathrm{h}$ network, being part of some core h-centrality network considered.

Comparing states with airport represented in the network, São Paulo and Pará have the largest number of airports in the network. However, the airports São Paulo in the network represent more than $30 \%$ of the approved flights while the Pará ones represent less than $3 \%$. We noted that in none of these 31 airports in Table 3 did the airport exhibit in its core airport outside the Brazilian territory during the analyzed period.

H-centrality for Brazilian airports

Considering a second-stage evaluation of the $\mathrm{h}$ index, we find that the Brazilian central network lists in Table 3 presents 6 airports with 6 or more destinations in their core h. Thus we can similarly, according to Figure 4, consider as 6 the type index $h$ of the airports of Brazil, in second order.

Thus, applying the concepts of air centrality to the airports network we can compare different countries or regions through the $\mathrm{h}$ type index model proposed here.

\section{RESULTS}

In this study we presented concepts of graphs, as well as the contextualization of the $\mathrm{h}$-index, much used in bibliometrics. In this association of graph theory and $h$-index, the h-centrality, formulated by Pereira et al. (2015a), was support for the verification of the h-central network among Brazilian airports.

As already verified by Ercsey-Ravasz et al. (2012), the central points of a network are verified by the most 


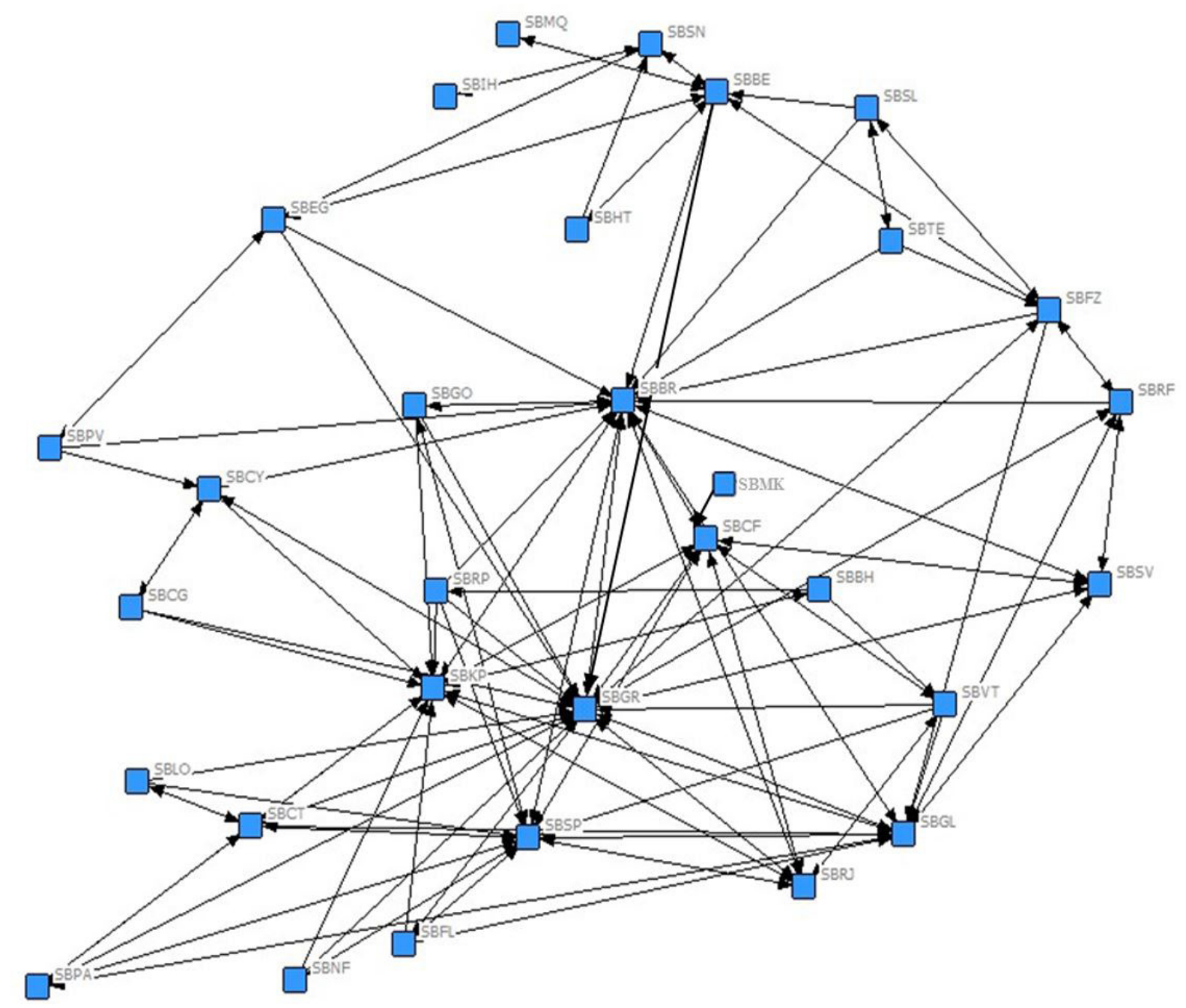

Figure 3. Brazilian H Network

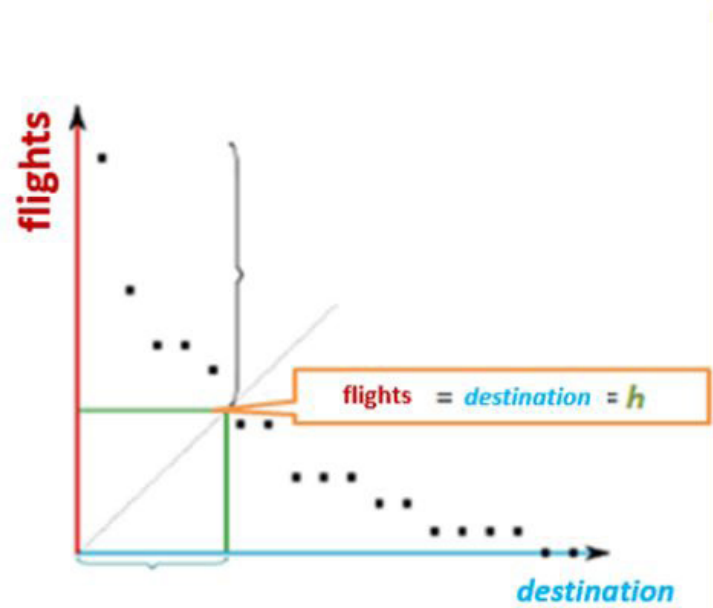

H Centrality - Airports

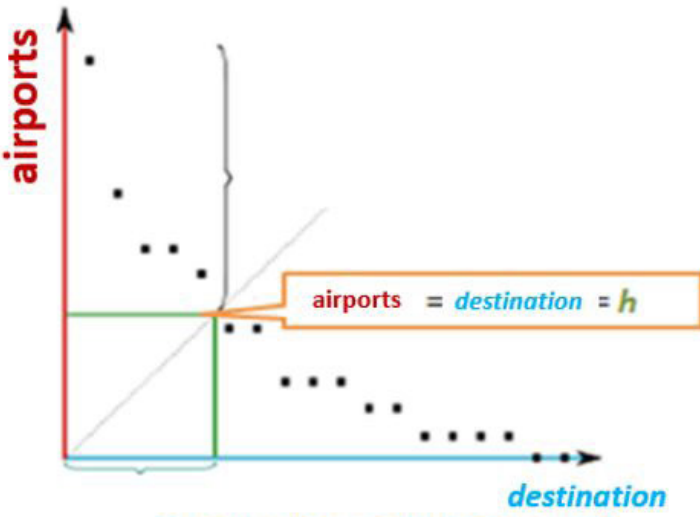

H Centrality - Airports Network

Figure 4. H Network for airport case 
impacting points, and the $\mathrm{h}$ - centrality analysis provides this identification. With the h-centrality measure, this study presented the h-central network comparing the index of each airport to define the relevance of the same, from the core list of each one.

The 31 Brazilian airports in Table 3 that represent the $\mathrm{h}$ network demonstrate the peculiar characteristics of the Brazilian aviation market, such as the distribution and concentration of operations. Highlight for the Southeast region as the largest number of airports in the network according to the measure analyzed.

As mentioned by Pereira et al. (2015a), this centrality measure presents the situation at the moment when the data were analyzed. In the original $\mathrm{h}$-index this notion reflects a history of the articles published by each author, but in the case of airports the market dynamics changes the behavior of the network.

As a result, airports outside the Brazilian territory were not found within the analyzed core list of the airports, nor of the universe of the 104 airports analyzed. This result does not mean the verification in a different period could not occur in the presence of foreign airports in the h-central network considering the position of Brazil for connectivity in Latin America and the world.

Additionally, further studies could be carried out to verify the interconnectivity of the global network, including Brazilian airports. And with the $h$-index evaluation in second order we can compare the relevance, connectivity and coverage of different regions. As we provide a list with main airports without prior action from any decision maker

Finally, another proposal for a future study could be to increase the data to consider the size of each airport as well as the types of aircraft that operate, to avoid discrepancies such as the State of São Paulo that has 4 airports in the network and these represent $30 \%$ of the national supply, in contrast, the State of Pará also has 4 airports in the $h$ network that add up to $3 \%$ of the offer.

\section{ACKNOWLEDGMENT:}

This study was financed in part by the Coordenação de Aperfeiçoamento de Pessoal de Nível Superior - Brasil (CAPES) - Finance Code 001.

\section{REFERENCES}

Agência Nacional de Aviação Civil (2016), "Anuário Transporte, 2016", available at: www.anac.gov.br (accessed 21 January 2018).
Batista, H.M.C.S., Rodriguez, M.V.C., Cardoso, K.A.W. et al. (2018), "The social network analysis and its contribution to the mapping of Scientific production in postgraduate programs", Brazilian Journal of Operations \& Production Management, Vol. 15, No. 2, pp. 330-4.

Bel, G. and Fageda, X. (2008), "Getting there fast: globalization, intercontinental flights and location of headquarters", Journal of Economic Geography, Vol. 8, pp. 471-95.

Bergiante, N.C.R., Soares de Mello, J.C.C.B., Nunes, M.V.R. et al. (2011), "Aplicação de uma proposta de medida de centralidade para avaliação de malha aérea de uma empresa do setor de transporte aéreo brasileiro", Journal of Transport Literature, Vol. 5, No. 4, pp. 119-35.

Borgatti, S.P. (2002), NetDraw: Graph Visualization Software, Analytic Technologies, Harvard.

Burrell, Q.L. (2007), "On the h-index, the size of the Hirsch core and Jin's A-index", Journal of Informetrics, Vol. 1, No. 2, pp. 170-177.

Doganis, R. (1992), The Airport Business, Routledge, London.

Ercsey-Ravasz, M., Lichtenwalter, R., Chawla, N.V. et al. (2012), "Range-limited centrality measures in complex networks", Physical Review. E, Statistical, Nonlinear, and Soft Matter Physics, Vol. 85, No. 6, pp. 66-103.

Fageda, X. (2014), "What hurts a dominant airliner at hub airports", Transportation Research Part E, Logistics and Transportation Review, Vol. 70, pp. 172-89.

Fageda, X., Suau-Sanchez, P. and Mason, K.J. (2015), “The evolving low-cost business model: Network implications of fare bundling and connecting flights in Europe", Journal of Air Transport Management, Vol. 42, pp. 289-96.

Hansen, M. (1990), "Airline competition in a hub-dominated environment: an application of noncooperative game theory", Transportation Research Part B: Methodological, Vol. 24, pp. 27-43.

Hirsch, J.E. (2005), "An index to quantify an individual's scientific research output", Proceedings of the National Academy of Sciences of the United States of America, Vol. 102, No. 46, pp. 16569-72.

Hirsch, J.E. (2007), "Does the $\mathrm{h}$ index have a predictive power", Proceedings of the National Academy of Sciences of the United States of America, Vol. 104, pp. 19193-8.

International Air Transport Association (2016), "The importance of air transport to Brazil - Oxford Report for 
IATA", available at: https://www.iata.org/en/iata-repository/ publications/economic-reports/brazil--value-of-aviation/ (accessed 21 January 2018).

Jaillet, P., Song, G. and Yu, G. (1996), "Airline network design and hub location problems", Location Science, Vol. 4, pp. 195-212.

Lu, H. and Mao, Y. (2015), "Evaluation of airport conditions to attract foreign low cost carriers: a case study of Taiwan", Journal of Air Transport Management, Vol. 42, pp. 297-305.

Martin, L., Puertas, R. and Calafat, C. (2015), "Efficiency of airlines: hub and spoke versus point-to-point", Journal of Economic Studies, Vol. 42, pp. 157-66.

McKinsey \& Company (2010), "Estudo do Setor de Transporte Aéreo do Brasil: Relatório Consolidado", McKinsey \& Company, Rio de Janeiro, RJ, available at: www.bndes.gov. br (accessed 5 February 2018).

Pereira, D.S., Brandão, L.C., Del Vecchio, R.R. et al. (2015a), "Centralidade aérea baseado no índice tipo h". in ANPET 2015: Congresso de Pesquisa e Ensino em Transportes, ANPET, Ouro Preto, MG.

Pereira, D.S, Costa, E.F., Wolff, M.G.C. et al. (2015b), “Pósanálise do índice $H$ e comparação com métodos ordinais multritério", Pesquisa Operacional para o Desenvolvimento, Vol. 7, No. 2, pp. 173-89.

Pereira, D.S., Rego, R.B., Muller, M.P. et al. (2017), “Os impactos das variáveis macroeconômicas no setor de aviação comercial brasileira", Engevista, Vol. 19, No. 4, pp. 1025-45.

Pereira, D.S., Brandao, L.C., Del-Vecchio, R. et al. (2018a), "Análise multicritério das centralidades de rede: estudo de caso em companhia aérea brasileira", Revista Espacios, Vol. 39, No. 4, pp. 1-25.

Pereira, A., Simonetto, E.O., Putnik, G. et al. (2018b), “How connectivity and search for producers impact production in Industry 4.0 networks", Brazilian Journal of Operations \& Production Management, Vol. 15, No. 4, pp. 528-34.
Reis, J.C., Torres, G.T. and Soares de Mello, J.C.C.B. (2017), "Identificação das Potências Olímpicas dos Jogos Olímpicos de 2016 Utilizando o Conceito de Núcleo h", Revista Meta: Avaliação, Vol. 9, No. 26, pp. 338-59.

Rubem, A.P.S., Moura, A.L. and Soares de Mello, J.C.C.B. (2015), "Comparative analysis of some individual bibliometrics indices when applied to groups of researchers", Scientometrics, Vol. 102, pp. 1019-35.

Schreiber, M. (2013), "How relevant is the predictive power of the h-index? As case study of the time-dependent Hirsch index", Journal of Informetrics, Vol. 7, pp. 325-9.

Van Raan, A.J. (2006), "Comparison of the Hirsch-index with standard bibliometric indicators and with peer judgment for 147 chemistry research groups", Scientometrics, Vol. 67, No. 3, pp. 491-502.

Wang, J., Mo, H., Wang, F. et al. (2011), "Exploring the network structure and nodal centrality of China's Air transport network: A complex network approach", Journal of Transport Geography, Vol. 19, pp. 712-721.

Wittmer, A. and Beritelli, P. (2011), "Comparing airline network structures: the case of Australia", in CAUTHE 2011: National Conference: Tourism: Creating a Brilliant Blend, University of South Australia, School of Management, Adelaide, Australia, pp. 1384-1400.

Wolff, M., Abreu, C. and Caldas, M.A.F. (2019), "Evaluation of road transport: a literature review", Brazilian Journal of Operations \& Production Management, Vol. 16, No. 1, pp. 96-10.

Yaru, D. and Lina, P. (2012), "Hierarchy of air freight transportation network based on centrality measure of complex network", Journal of Transportation Systems Engineering and Information Technology, Vol. 12, No. 3, pp. 109-14.

Zhang, S., Derudder, B. and Witlox, F. (2014), "The determinants of full-service carriers airfares in European hub-to-hub markets", European Journal of Transport and Infrastructure Research, Vol. 14, No. 4, pp. 449-67.

Received: 26 Mar 2019

Approved: 16 Apr 2019

How to cite: Pereira, D.S. and Mello, J.C.B.S. (2020), "Brazilian airports network evaluation", Brazilian Journal of Operations \& Production Management, Vol. 17, No. 1, e2020833. https://doi.org/10.14488/BJOPM.2020.008 